A Laboratory Procedure to Facilitate Color Conscious Racial Socialization Methods Among White Parents in the U.S.

\author{
Sylvia Perry*1,2,3 \\ Jamie L. Abaied ${ }^{4}$ \\ Allison L. Skinner-Dorkenoo ${ }^{5}$ \\ Sara F. Waters ${ }^{6}$
}

${ }^{1}$ Department of Psychology, Northwestern University, ${ }^{2}$ Department of Medical Social Sciences, Northwestern University, ${ }^{3}$ Institute for Policy Research, Northwestern University, ${ }^{4}$ Department of Psychological Science, University of Vermont, ${ }^{5}$ Department of Psychology, University of Georgia, ${ }^{6}$ Department of Human Development, Washington State University

\begin{abstract}
Author Note
The authors would like to thank the Intergroup Relations Working Group (IGR) attendees for their feedback on an early draft of this manuscript, Brandon Davis for his help with the preparation of the manuscript, and the Social Cognition \& Intergroup Processes (SCIP) lab for their assistance with data collection and coding.

*Subsequent correspondence can be directed to sylvia.perry@ northwestern.edu
\end{abstract}




\begin{abstract}
For years, White U.S. parents have strived to raise colorblind children, yet mounting evidence indicates that color conscious racial socialization is needed to cultivate an anti-racist orientation. The current work evaluates a new semi-structured laboratory procedure to facilitate color conscious racial socialization in 87 White parent-child (8-12-year-olds) dyads. Contrasting with prior research, qualitative findings revealed that most parents used racial labels and color conscious racial socialization methods. However, a subset of parents pushed back against the color conscious guidance, encouraging racial ignorance or external attributions for racist behaviors. This work highlights promising evidence of a means for facilitating color conscious socialization in White families, and additional intervention targets for future efforts to foster antiracism in White families.
\end{abstract}




\section{A Laboratory Procedure to Facilitate Color Conscious Racial Socialization Methods Among White Parents in the U.S.}

The common idea of claiming "color blindness" is akin to the notion of being "not racist"-as with the "not racist," the color-blind individual, by ostensibly failing to see race, fails to see racism and falls into racist passivity. The language of colorblindness-like the language of "not racist"-is a mask to hide racism.

—Kendi (2019, p. 10)

In the decades following the U.S. civil rights movement, many U.S. residents shaped their identities around being non-racist. Colorblind ignorance of race and ethnicity was held up as the epitome of being "not racist," with the notion that those who do not see race certainly cannot be racist. Yet, as Ibram Kendi’s (2019) quote highlights, this kind of colorblindness more so blinds us to racism, than it does to race. The antidote to this is anti-racism, an orientation of actively identifying, acknowledging, and working against the racist system of attitudes, beliefs, and policies that have perpetuated racism in the U.S. for hundreds of years. Thus, by socializing children to recognize racism, and acknowledge and address race-related issues (practices referred to as color conscious socialization in the racial socialization literature), we can cultivate antiracism.

How parents teach their children about race and racism has important implications for the development of their children's racial attitudes, but compared to families of color, we know much less about how White American parents socialize their children about race (Loyd \& Gaither, 2018; Scott et al., 2020). The limited research suggests that some White parents recognize the importance of discussing race with their children, and many even identify themselves as anti-racist (Hagerman, 2017; 2018). Yet, contrary to these stated beliefs, across 
several studies, evidence suggests that the majority of White parents in the U.S. $(\sim 70 \%)$ tend to avoid discussing race with their children, and many wait for their child to bring up the topic (e.g., Abaied \& Perry, 2021; Perry et al., 2019; Zucker \& Patterson, 2018), which is the opposite of an anti-racist socialization approach.

Research has identified a number of different reasons why White parents typically do not discuss race with their children. When asked why they avoid discussing race, some White parents report feeling unprepared for these discussions (Underhill, 2018) — even when provided with take-home instructions (Vittrup \& Holden, 2011) — and some fear that discussing race with their children could actually increase racial bias (Vittrup, 2018). However, recent research with White parents of White children between the ages of 8 and 17 suggests that White parents' avoidance of racial discussions is rooted in more than a lack of preparedness. Specifically, some White parents reported actively avoiding discussing racism in an effort to shield their children from the realities of racism $(3 \%-37 \%)$ or believing race is irrelevant to their families $(28 \%-55 \%$; Abaied et al., 2021; Abaied, \& Perry, 2021). Meanwhile, by middle childhood, the majority children of color in the U.S. are already experiencing and suffering the negative consequences of daily discrimination, often perpetrated by White children (Pachter et al., 2010; Seaton \& Douglass, 2014). Thus, it is clear that racism is a critical topic to address even in childhood. Previous recommendations from the racial socialization and intergroup relations research suggest that there are specific practices that may be targeted in order to facilitate a color conscious style of racial socialization in White families. For example, research has shown that avoiding mentioning race can have negative implications for White children's and adults' attitudes and behaviors toward people of color, reducing the likelihood that they can recognize and identify racial discrimination (Apfelbaum et al., 2008; Apfelbaum et al., 2010). In contrast, a 
color conscious approach, in which race is mentioned in appropriate contexts (e.g., when racial prejudice occurs) and children are taught the realities and history of racism in school settings, has been shown to reduce children's prejudice and increase intergroup empathy (Hughes et al., 2007). Beyond mentioning race in appropriate contexts, evidence suggests that, unless White parents explicitly acknowledge the perpetrator of racist behaviors, their children may infer that perhaps the victim of racial prejudice was responsible for or deserving of the discriminatory act (Brey \& Pauker, 2019; Hetey \& Eberhardt, 2018; Olson et al., 2011; Roberts \& Rizzo, 2020; Vittrup, 2018).

Empathy and perspective taking are also important components of an anti-racist orientation to racial socialization. Both survey and experimental research have shown that, relative to Black people, White people are less aware of the impact that racial discrimination has on Black people, less likely to believe that racially charged events, such as officer involved shootings, occur as a result of racism, and less likely to perceive subtle racism as a form of racism (Pew Research Center, 2014; Jefferson et al., 2017; Neville et al., 2000; Sommers \& Norton, 2006; Sue et al., 2007). One theorized contributor to these tendencies is the fact that White people, on average, have few quality interactions with Black people, which has been linked to lower outgroup empathy (Boisjoly et al., 2006; Cox et al., 2016; Jones, 2014; Sigelman et al., 1996; Masten et al., 2010; Pettigrew \& Tropp, 2000). Evidence suggests that encouraging majority group members to empathize and perspective take with the victims of prejudice may facilitate prejudice reduction (Batson \& Ahmad, 2009; Dovidio et al., 2004; Vescio et al., 2003). This process allows people to put themselves in another person's shoes (e.g., how would I feel if someone treated me differently because of the group to which I belong?; Batson \& Ahmad, 
2009), which may increase the likelihood that White individuals will be willing to confront the realities of racism (Cox \& Devine, 2019: Dovidio et al., 2004; Mallett et al., 2008)

Labeling and explicitly challenging racism are also key elements of anti-racist parental racial socialization. These practices help counteract the effects of the colorblind messages children are routinely exposed to in contemporary U.S. society, which are known to reduce awareness of and responsiveness to racism (Apfelbaum et al., 2010). Ashburn-Nardo et al.'s (2008) model for confronting prejudice indicates that awareness of racism and understanding of its impacts are crucial to spurring social action. This kind of social realignment, to establish antiracism as the norm, has been recognized as a key step on the path toward social equity (Nelson et al., 2011). By gaining practice at identifying and discussing some of the various ways that racism plays out in society, children will not only be better prepared to recognize racism when they see it, but also be better equipped with the language to explicitly identify and challenge racism among their peers (Araujo \& Strasser, 2003). Thus, beyond merely influencing the attitudes of the child who experiences this type of racial socialization, color conscious racial socialization may have broader impacts on social norms surrounding tolerance of racism (Nelson et al., 2011). We sought to develop a guided discussion task that would provide opportunities for parents and their children to (a) identify, discuss, and label racism in different contexts, (b) use explicit racial labels in appropriate contexts, (c) attribute racist acts to the perpetrator so that children can understand that the victim is not to blame for racism, and (d) take the perspective of and empathize with the victims of racism. We theorized that providing these opportunities would facilitate anti-racist racial socialization methods in White parents (i.e., parents who discussed racism in a more color conscious way). 


\section{The Current Study}

The focus of the current work was to challenge White parents' tendency to avoid conversations about race by providing structured prompting for them to actively converse with their child about racism in a color conscious way that openly acknowledges and condemns racism and values diverse perspectives. This is important, because, in order for White parents to raise anti-racist children, they must take an active approach to discussing the realities of (systemic and historical) racism and pointing out racism when they observe it with their children. We drew from extant theory and research to create prompts based on the racial socialization and intergroup relations literature, focusing on evidence-based approaches that have been shown to facilitate prejudice reduction and increased outgroup empathy. We created emotionally evocative stimulus videos to facilitate color conscious discussions in parent-child dyads. Interpersonal racism manifests in a number of different ways, but White people in the U.S. often fail to recognize and label subtle forms of racism, such as feeling uncomfortable around Black people or confusing one Black person with another Black person (Sommers \& Norton, 2006). As such, we designed stimulus videos that would provide examples of both subtle and blatant forms of racism. We also designed these scenarios to provide opportunities for parents to recognize and challenge a number of common racist beliefs (e.g., outgroup homogeneity) and stereotypes about Black people in the U.S. (e.g., criminality, dangerousness, unintelligence).

In this study, we report a detailed qualitative analysis of racial socialization during the task, including racial ideologies endorsed by parents, the degree to which parents engaged with versus ignored race, and parents' interpretations of and reactions to the stimuli we provided. We will contextualize these findings within the extant literature on racial discussions in White 
families and demonstrate that our paradigm is well suited to help White parents overcome their reluctance to discuss race with their children.

We focused on parents of youth in middle childhood (ages 8-12), at which point children have developed an abstract understanding of race (Hughes et al., 2007), of racial categories and stereotypes (Aboud, 2008), and of racial prejudice (Killen et al., 2011; Rutland \& Killen, 2015); thus, children in this age group should be capable of understanding and discussing depictions of racial prejudice. Moreover, we reasoned that — although these tendencies would not be absentby middle childhood, White parents might be less likely to avoid engaging with their children on topics related to race and racism, or engage in shielding (hiding negative information from children as a means of protecting them), than they would with younger children. Therefore, this age group was particularly well-suited to be receptive to our procedure.

\section{Method}

\section{Participants}

We recruited 87 self-identified White parents $\left(91.5 \%\right.$ female; $M_{a g e}=42.57$ years, $S D_{\text {age }}=$ 5.14) and their (parent-identified) White children (53\% female; $M_{\text {age }}=8.95$ years, $\left.S D_{\text {age }}=1.16\right)$ from the greater Chicago metropolitan area. Parents were highly educated (40\% held a bachelor's degree, and 35\% held a graduate degree), middle-class and above (78\% reported a household income of over $\$ 100,000)$, majority liberal to liberal-leaning (66\% liberal to liberallearning, $19 \%$ moderate, $15 \%$ conservative to conservative-learning), and $95 \%$ reported that they were married. During their lab visit, parent-child dyads engaged in a semi-structured discussion task in response to animated videos of interactions between various Black children and White children. 


\section{Experimental Procedure and Stimuli}

The video stimuli included depictions of interracial interactions in which (a) no bias was displayed by the White child (control condition), (b) the White child displayed subtle bias against a Black child (e.g., a White child feeling uncomfortable around a Black child; $\underline{\text { subtle }}$ example) or (c) the White child displayed blatant bias against a Black child (e.g., a White child calling a Black child names; blatant example). During their prompted discussions, families first observed scenarios in which a White child was explicitly described as being prejudiced toward a Black child (e.g., "Tiffany thinks that all Black kids are dumb..."; which set the norm of using racial labels in the context of the racist incident). The racially biased incidents were adapted from the lay theories of what constitutes racism outlined by Sommers and Norton (2006). All dyads began with a control condition video, which was followed by two incidents of subtle bias, another control video, then two more incidents of subtle bias. Lastly, participants watched one more control video, followed by three incidents of blatant bias.

Immediately after each video, dyads were prompted to discuss their thoughts and reactions for 2 minutes. After each of the first three videos, dyads received a general prompt: "Please take the next few minutes to talk out loud about this video." For the remaining videos, dyads received more structured prompts (Figure 1). Parent-child conversations were transcribed from video recordings.

In order to facilitate color conscious conversations during their prompted discussions, parents were asked to consider the following (see Figure 1). (1) In order to encourage parents to use racial labels within an appropriate context (e.g., when pointing out and discussing prejudice) and to discourage them from using colorblind methods, the videos explicitly mentioned race. For example, our video narrator explicitly stated that the White child was excluding or feeling 
negatively about the Black child because they were Black. (2) In order to provide parents with an opportunity to discuss that the behaviors they were observing with their child (i.e., the White child being prejudiced toward the Black child) were to be attributed to the White child and their behavior, as opposed to the Black child, a prompt asked dyads to discuss why the White child behaved the way they did. (3) In order to encourage parents to discuss empathizing and perspective taking with the Black child who was the victim of racial prejudice, one prompt asked dyads to discuss how they thought the Black child felt and how they would have felt if they were that child. (4) Finally, we included two prompts designed to encourage parents to model acknowledging and addressing racism. One prompt asked dyads to discuss whether they thought the behavior of the White child in the video was prejudiced (after prejudice was defined as a person having a "negative opinion of someone because of the group they belong to"). The other discussion prompt asked dyads to discuss whether there was something wrong with the White child's behavior. We anticipated that the use of these prompts would help facilitate color conscious racial socialization among parents, by facilitating opportunities for them to point out prejudice and the problematic nature of the White child's behavior in the video. 


\section{Figure 1}

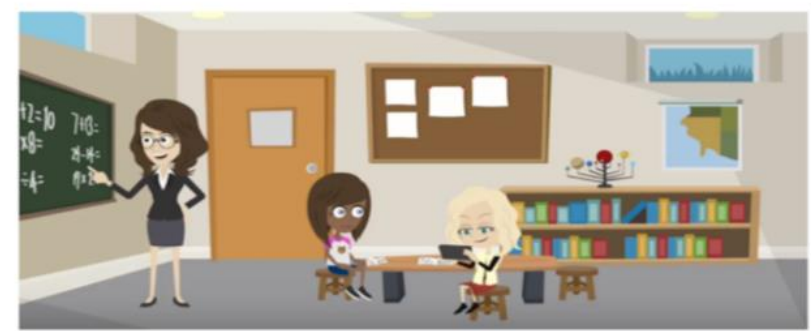

Tiffany thinks that all Black kids are dumb. The other day when the teacher wasn't looking, she called Casey stupid.

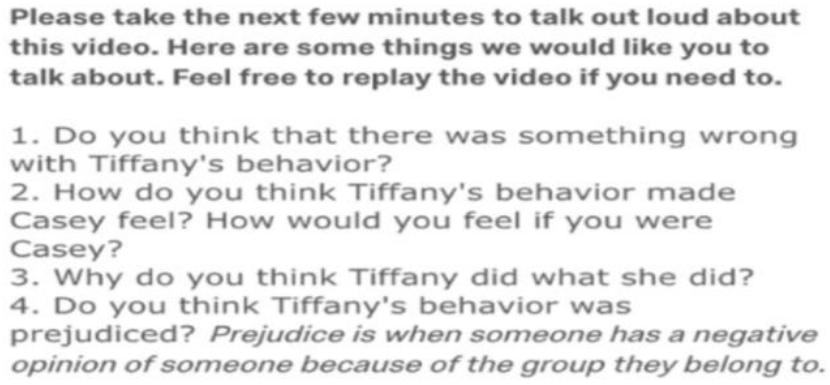

Note. Screenshot of an example of the video stimuli and race discussion prompts.

\section{Conversation Content Coding}

The development of the coding scheme involved a multi-step process. Given that our methodology was informed by prior theory and research, but also quite novel in its design, we elected to combine both inductive and deductive approaches to ensure our coding scheme captured the full range of parent racial socialization messages during the task. First, following a deductive or "top-down" approach, the first and third authors defined codes to capture racial socialization messages that have emerged in prior work on racial socialization in White families (e.g., Abaied \& Perry, 2021; Pahlke et al., 2012; Vittrup, 2018; Zucker \& Patterson, 2018). Next, following an inductive or "bottom-up" approach, the authors reviewed randomly selected videos to explore other themes in parent responses that were not captured by the top-down approach. The authors then fine-tuned the coding scheme to better capture nuanced distinctions of interest that emerged within these themes (See Table 1 for a detailed description of the coding scheme). 
Three sets of trained research assistants coded the parent portion of each transcript for the presence or absence of these eight elements. Each set of coders was composed of two research assistants who coded two to three of the elements. The first set of coders (an Asian American woman and a White woman) coded colorblind language and redirecting away from race. The second set of coders (a Hispanic/Latinx woman and a White and Native American woman) coded benefit of the doubt, blaming adults or media, and blaming the Black child. The last set of coders (a South Asian woman and a White and Japanese American man) coded pointing out prejudice, use of racial language, and connections to societal racism. The coders showed between $84 \%$ and $99 \%$ agreement, and discrepancies were resolved by a third coder. Final inter-coder reliability was calculated using the Intraclass Correlation Coefficient (ICC). Reliability was satisfactory for pointing out prejudice (.68), blaming adults or media (.94), redirecting away from race (.62), connections to societal racism (.62), benefit of the doubt (.67), and use of racial language (.80). ICCs were low for colorblindness (.25) and blaming the Black child (.40); however, this was likely due to low variability in the sample, as these codes were rare, and percentage interrater agreement for these variables was high (Colorblind 92.5\%; Blame 99.2\%).

\section{Results}

After the coding process was complete, the authors collaboratively organized the eight codes above into racial socialization themes. Specifically, we focused on identifying groups of socialization messages that communicated similar approaches to interpreting and describing the vignettes. We identified three broad themes in parents' racial socialization messages during the discussion: color conscious socialization, racial ignorance socialization, and external attributions. Before examining these broader themes, we first examined parents' use of racial language during the task, broadly — given that racial language may be used in a variety of ways (e.g., while 
engaging in anti-racist socialization methods or racist socialization methods). In addition, we explored the degree to which parents contradicted themselves during the discussion task by voicing both color conscious and racial ignorance messages. Within each theme, we also explored similarities and differences in racial socialization during discussions of subtle versus blatant forms of racism ${ }^{1}$.

\section{Use of Racial Language}

We first examined the degree to which parents used words to explicitly refer to race during the discussions (Table 1). A majority of parents voiced at least one word that explicitly references race, such as "Black," "White," or "race," in both the blatant and subtle conditions. When discussing blatant examples of racism, $66.7 \%$ of parents used at least one racial term; when discussing subtle examples of racism, $77 \%$ of parents used at least one racial term.

Racial language emerged in a variety of ways. Use of racial terms emerged in the context of both the color conscious (e.g., "I think that he has some prejudice based on like what society has taught him to feel about Black people, which isn't right.") and racial ignorance themed (e.g., “could a White kid pick on a Black kid without it being a race issue?" ) socialization messages. Racial language also emerged when dyads were simply reviewing the details of the vignette (e.g. “Well, what did they say - didn't they say that he doesn't like Black people?”). Finally, at times, parents used racial labels when referencing people the dyad knows in real life (e.g., "He's actually Asian. He's not African American.’).

\footnotetext{
${ }^{1}$ Here we exclusively focus on parent responses in the prompted conditions.
} 


\section{Table 1}

\section{Prevalence of Racial Socialization Messages}

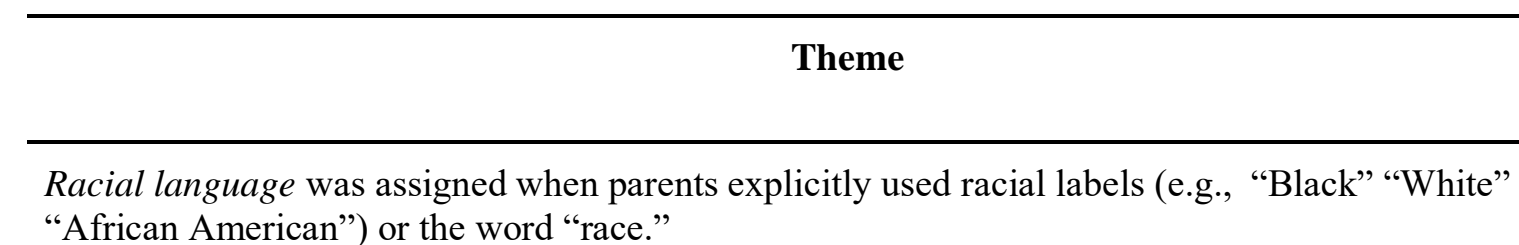

\section{Color Conscious Socialization}

Subtle Condition $\%$ of Parents attitudes or behavior as prejudiced.

Connections with societal racism was assigned when parents talked about racism beyond what was portrayed in the video, such as making connections to structural racism or examples of racism that they had witnessed in their own lives.

\section{Racial Ignorance}

Benefit of the doubt was assigned when parents suggested that the White child's behavior was unintentional or that the White child's intentions couldn't be known.

Redirecting was assigned when parents redirected the conversation to topics unrelated to race.

Colorblind messages was assigned when parents used messages that dismissed the significance or relevance of race (e.g., "What matters is what a person is like inside, not a person's skin").

\section{External Attributions}

Blaming adults or media was assigned when the parent attributed the White child's attitudes or behavior to something external (e.g., media, environment, parental influence).

Blaming the Black child was assigned when parents focused on the actions of the Black child and spoke about what they could have done differently in that situation.
$77.0 \%$

$60.9 \%$

$59.8 \%$

Blatant Condition

$\%$ of Parents

$66.7 \%$

$82.8 \%$

$81.6 \%$

$4.6 \%$

$55.2 \%$

$48.3 \%$

$13.7 \%$

$10.3 \%$

$24.1 \%$

$19.5 \%$

$23 \%$

$2.3 \%$

$1.1 \%$ 


\section{Color Conscious Racial Socialization}

Two types of socialization messages emerged during the discussion that orient the child toward noticing that racism is happening and understanding that racism is wrong: pointing out prejudice and connections to societal racism (Table 1). A majority of parents voiced color conscious racial ideology at some point during the discussion, but rates varied by condition. In the blatant condition, $82.8 \%$ of parents made at least one color conscious statement, whereas in the subtle condition, $60.9 \%$ made at least one color conscious statement. Thus, although the blatant condition elicited more color conscious statements from parents, relative to the subtle condition, both conditions elicited color conscious socialization messages from a majority of parents and at much higher rates compared to prior studies of White parents' discussions of race. We discuss specific types and examples of color conscious racial socialization below.

Pointing out Prejudice. The majority of the sample explicitly labeled that racial prejudice was happening in the vignette in both conditions, with higher rates emerging in discussions of blatant racism $(81.6 \%)$ compared to subtle racism $(59.8 \%)$. The vast majority of these comments were in response to the discussion prompt that asked the dyad if they thought the White child's behavior was prejudiced. For example, in response to a video in which a White child calls a Black child stupid (blatant racism):

Parent: Do you think Erika's behavior was prejudiced?

Child: Yeah.

Parent: Yeah, I do too. Have — have you ever been made to feel stupid for-

Child: Uhh.

Parent:- how somebody thinks of you?

Child: Yeah.

Parent: Because they've stereotyped you?

In response to videos depicting blatant racism (such as the scenario above) some parents indicated to their child that they thought the prejudice in the video was very obvious or clear:

Parent: So why did she do that, she's just wrong (pause, sigh) do you think Erika's behavior was prejudiced? 
Child: Yeah

Parent: Duh, right?

Some parents easily picked up on the prejudice occurring in examples of subtle racism as well, such as a White child who thinks all Black people look alike getting two Black children (who look visibly quite distinct) mixed up all the time or a White child choosing to play with White kids instead of Black kids:

Parent: Why do you think Matt did what he did? Cuz he's a jerk! Do you think his behavior was prejudiced?

Child: Yes.

Parent: Obviously. He even said it's prejudiced in the first line! [Replays video] There you go! Pretty much all prejudice right there.

Parent: Do you think Stephanie's behavior is prejudiced? Prejudice is when someone has a negative opinion of someone else because of the group that they belong to. I think the answer to this is very clear.

Child: Yes

Parent: Yes, and is that okay?

Child: Nuh-uh.

Parent: Nuh-uh.

Each vignette provided information to help the dyad understand that racial prejudice was motivating the White child's behavior (e.g., "Erika thinks all Black kids are dumb," "Tom feels uncomfortable around Black people"). Some parents incorporated these details into their conversation with their child about blatant examples of racism:

Parent: I think he's prejudiced.

Child: Why?

Parent: Well, what did they say — didn't they say that he doesn't like Black people?

Child: Mm, yeah, it did say that.

Parent: So he's judging them-judging them on the color of their skin. What if the person's a really nice person, the boy?

Child: And what he looks like, probably.

Another parent adopted a similar approach:

Parent: Alright I know kids call each other stupid in your school.

Child: Yeah but it has nothing to do with what they look like.

Parent: In this- yeah. I mean here it does cause she said it was-

Child: Yeah-

Parent: They said it was in the voice over.

Child: But the thing is that kids call each other stupid-

Parent: Yeah- 
Child: But it's not to do with-

Parent: It's not - but it's not allowed right.

Child: It's not allowed. But it's nothing to do with if you're black or white or [?]

Parent: Yea. But if somebo[dy]- I mean any mean thing that you say because somebody's Black is

bad.

Child: Yeah.

Parent: Obviously.

Referring to information provided in the story also occurred in parent responses to videos

depicting subtle racism:

Parent: Okay, do you think there was something wrong with Stepanie's behavior?

Child: eah

Parent: Yeah, what was wrong with her behavior?

Child: She didn't like Black people.

Parent: She is only choosing White kids to play with.

These examples suggest that parents were able to use the context provided in each vignette to help their child understand that racial prejudice had occurred.

Some parents also expressed concern for the Black child in the video when they pointed out prejudice, such as this response to a White child calling a Black child stupid (blatant racism):

Parent: ... did she have a right to say that to uh Tammy?

Child: No

Parent: No this, these videos go against everything that we teach (laugh)

Child: Yeah

Parent: Yeah (pause) so poor Tammy, having to deal with Erika

Child: Mhm

Parent: Erika needs some uh, sensitivity training, they need a better guidance counselor at their school, maybe they don't have one at all, I feel bad for Tammy.

Expressions of empathy often occurred in response to the prompt asking how the Black child might feel and how the target child would feel if they were the Black child, such as this response to a video in which a White child kicks a ball at a Black child on purpose (blatant racism):

Parent: Okay Do you think that there was something wrong-

Child: Yes

Parent: with Nathan's behavior?

Child: Yes

Parent: I agree. Do you think that Nathan's behavior made Jeff, how do you think Nathan's behavior made Jeff feel?

Child: Sad, umm 
Parent: And how would you feel if you were Jeff?

Child: Very sad.

Parent: And I would feel sad and I'd be upset.

Another dyad expressed empathy in response to a video in which a Black child is blamed for taking a White child's belonging (subtle racism):

Parent: Umm, how do you think Chris' behavior made Jacob feel? How do you think Jacob felt? Child: Sad.

Parent: Sad, I think he probably felt wrongly accused, right? Umm, how would you feel if you were Jacob?

Child: Bad.

Parent: Bad?

Child: Sad, sad.

Parent: Sad, me too.

In sum, the guided discussion task was largely successful in eliciting discussion of the racism that occurred in the vignettes.

Connections to Societal Racism. A small number of parents $(4.6 \%$ in the subtle condition, $5.7 \%$ in the blatant condition) went beyond simply pointing out that prejudice had occurred, discussing the negative impact of racism in a deeper way that went beyond the example in front of them. For example, this parent connected the story about a Black child getting blamed for taking a White child's missing belonging (subtle racism) to the racism that Black people experience more broadly:

Parent: How would you feel if you were Jacob?

Child: Sad, that every, and a little bit, cus like everybody cus um, he'll keep saying that he took his pen, all, all the time.

Parent: Yeah, so if I were Jacob I might feel like nobody in society would trust me, nobody that was White would trust me. You know that sometimes Black boys have that problem? Child: Yeah

Parent: In our culture that people, especially White people, think that they are bad.

Some parents brought up systemic racism in settings such as law enforcement and education. For example, this parent mentioned police brutality in response to a vignette about a White child kicking a ball at a Black child (blatant racism):

Parent: Sometimes in our society White people do hurt Black people. It makes me sad. 
Child: Me too.

Parent: Like sometimes, you know how sometimes the police are more likely to shoot a teenager if it is a Black boy?

Child: mhm.

Parent: Even if he is doing nothing wrong. So it's actually kind of dangerous to be a Black boy in our society.

A few parents brought up racial segregation of schools and neighborhoods, such as this response

to a Black child being blamed for a White child's missing possession (subtle racism):

[It] concerns me because so many schools are still racially segregated because of neighborhoods.

There aren't that many White kids in CPS [Chicago Public Schools] at all because a lot of White kids in the city go to private school or Catholic schools. They're not even with-and that's in the city like if you live in the suburbs White are really White or like rural areas which are really White. So many people just don't have that much interaction.

Another parent connected the vignette in which a White child thinks all Black children are dumb

and calls a Black child stupid (blatant racism) to her memories of racism in ability tracking in

elementary school:

Parent:[ gasps] Oh my gosh.

Child: [ makes uncomfortable noise].

Parent: What do you think? That's so rude and so inaccurate. I wonder where she gets that stereotype from? What do you think, do you think White kids are smarter?

Child: No

Parent: No ( laughs) Not all White kids. Some White kids. And some other White kids. But some Black kids are smarter than White kids. And all people of color. [pause] I told you about when I was in 4th grade, when I was 10. That's when I noticed something was up. Cause starting in fourth grade, because I went to a really small school where there was only one class for every grade, so the quote unquote best readers in the class ... went up to 5th grade for reading class. And it was all White 4th graders, so when we went to 5 th grade all the White 5th graders had gone to 6th grade so it was all the kids of color. We were a year younger than them and we were still stronger readers than them and I was really confused and I asked my mom like what is up with this because $I$ know that not all White people are smarter than people of color. And there was a White boy in our group who I thought was pretty dumb who I didn't think should be in our group and he got to go up with us. And there was a Black kid and a Latino kid who I thought should've gone up with us, since she was one of the smartest kids in the class. And I just didn't understand. And I thought it was pretty weird. And in retrospect it was a White male teacher who made that decision.

Child: Of course it was.

Parent: It was the only White male teacher I had in 9 years. And he picked all the White kids.

These comments help the child connect what they are seeing in the hypothetical scenario depicted in the video to broader patterns that are present in society. They also draw children's 
attention to systemic racism in housing, policing, or education. These parents engaged in a deeper conversation about race than what was directly asked of them during the task.

\section{Racial Ignorance Socialization}

Three types of socialization messages emerged that redirected away from the topic of race or called into question the notion that racial prejudice occurred in the vignettes (Table 1). This included giving the White child the benefit of the doubt, redirecting the child's attention away from race, and colorblind statements (i.e., implying that race is surface-level and/or does not matter). The percentage of parents who made at least one racial ignorance statement was slightly lower in the blatant condition (42.5\%) compared to the subtle condition (55.2\%). In contrast to prior research, racial ignorance was less common in the sample than color conscious socialization.

Benefit of the Doubt. The most common form of racial ignorance socialization across both conditions was the parent giving the White child the benefit of the doubt $(48.3 \%$ in the subtle condition, $32.3 \%$ in the blatant condition). One form of this sentiment involved the parent finding ways to suggest that the White child did not intend to be hurtful to the Black child. For example, in reference to a White child thinking all Black children look alike (subtle racism), one parent stated:

Parent: Do you think there was something wrong with Matt's behavior? Child: "Uhhhh no."

Parent: I don't think so. I think- I think it was an accident.

A few parents attempted to provide an alternative explanation for the child's behavior racial prejudice, such as this response to the story about a White child thinking all Black children are dumb (blatant racism): “See I sometimes I think it's—Erika's feels bad about herself so she['s]...tryna bring other people down." In other cases, the parent seemed to imply that there 
was no way to know whether or not the White child meant to be prejudiced. For example, in reference to a White child being uncomfortable around Black children (subtle racism), one parent said: "we don't actually know whether he was, like, mean or bad." In reference to a White child never picking Black children to play soccer (subtle racism), another parent said "I can't tell if she's picking one person because they're better at soccer or because they for sure have White skin over the other- over the other girl. You know, it's hard to say."

Some parents seemed resistant to the idea that a White child would be racist even when their own child seemed to disagree. For example, in reference to a White child thinking Black children are dumb (blatant racism), one parent said:

Parent: Why do you think Erika said that?

Child: Because she thinks all Black people are dumb.

Parent: Well that's what the commentary says. I'd like to- I hope not. I'd like to think not.

It is noteworthy that this form of colorblind socialization was somewhat more common in the subtle condition; thus, parents were more likely to make excuses for the White child's behavior when the racism depicted in the vignette was less obvious. However, even in the subtle vignettes, dyads were provided with some context for the White child's behavior (e.g., "X feels uncomfortable around Black people," or "X thinks all Black people are trouble-makers"). Thus, parents had to actively disregard the information that we initially provided them (i.e., the fact that the behavior or belief should be directly attributed to the child's negative perceptions of Black children).

Redirecting Away from Race. A small subset of parents found ways to redirect the conversation away from the issues of race or racism. This occurred at similar rates in discussions of subtle racism $(13.7 \%)$ and blatant racism $(12.6 \%)$. Some parents redirected away from racism as an explanation for the White child's behavior, such as this response to a White child thinking all Black children look alike (subtle racism): 
Parent: You think that there was something wrong with Matt's behavior?

Child: Only a little because like I mean like they do have their different facial features.

Parent: Yeah.

Child: Like you can tell them apart.

Parent: Yeah. One of them has black hair-

Child: I think he just is not observant.

Parent: Yeah it may not be racism he just doesn't-

Child: he's just not observant.

Other parents went out of their way to redirect their child after their child stated that they

believed the White child's behavior was prejudiced, such as in this dyad's discussion of a child

who is always mean to Black kids (blatant racism):

Parent: Okay, do you think Nathan's behavior was prejudiced?

Child: "Yes."

Parent: Okay, um let me ask you something. Could a kid be getting picked on by a kid-could a White kid pick on a Black kid without it being a race issue? Could it be about that personChild: "Yes, some people are just that way."

Parent: Okay. Oh.

Child: "They might also pick on White kids-"

Parent: Mhm.

Child: "like everyone."

Although these comments were infrequent in the sample, they are concerning, because parents redirected their children to non-racial explanations even when race was explicitly said to be relevant, concluding that if the Black child in the video was treated badly, it was not due to racial prejudice.

Colorblind Messages. Use of language that downplays the significance or relevance of race emerged at similarly low rates in discussions of subtle racism (10.3\%) and blatant racism (12.6\%). For example, one dyad initially considered that race could be a factor in a White child thinking all Black children are dumb, but subsequently rejected the idea that race should be taken into account when interpreting others' behavior:

Parent: And maybe in her mind, the reason is because she's Black. Child: And that's not really a reason.

Parent: No. It's definitely not a reason, because it's the color of your skin, what does that mean? It's just the color. It doesn't mean anything. 
Another parent expressed colorblindness in a way that downplays racial differences and instead emphasizes sameness between races when discussing a White child who tells her friends not to play with Black kids (blatant racism):

Parent: What do they do?

Child: Same as White.

Parent: Exactly, honey, the same as White — or any color, person of color.

\section{External Attributions}

This theme involved parents attributing prejudice to someone or something other than the White child. This is similar to offering the White child the benefit of the doubt, but rather than simply questioning the White child's intentions, parents identified something external to the interaction that might explain the White child's behavior (other than racial prejudice). External attributions were made by $20.7 \%$ of parents in the subtle condition and $24.1 \%$ in the blatant condition; thus, this theme was much less prevalent in the sample compared to color conscious socialization.

Blaming Adults or the Media. This form of external attribution involved parents suggesting that the White child in the vignette learned their racially prejudiced behavior from some external source; this emerged among $19.5 \%$ of parents in the subtle condition and $23 \%$ of parents in the blatant condition. The most common form of external attribution was suggesting that the White child's parents had taught them to behave that way toward Black children. For example: "He probably- how do you think he learned that? Maybe from his parents, or he overheard his parents say something bad," or, "You know why that happens a lot of times? Because a lot of times, kids behave how parents are taught- they learn [from] them [how] to behave." Other parents suggested that the White child had heard it from someone else without specifically identifying who: "Somebody has been influencing her and giving her wrong information or not giving her the correct information, right? She heard it somewhere." A few 
parents mentioned the possibility that the White child could have been exposed to racism on TV and decided to mimic it: ""From what he sees on TV or like his parents like FOX news." What all of these comments have in common is a reluctance to hold the White children in the videos accountable for their racist actions. These comments do not necessarily contradict the idea that the White child exhibited racial prejudice; rather, they seem to reflect parents' desire to avoid placing fault for that prejudice entirely on White children's shoulders.

Blaming the Black Child. A very small percentage of parents $(2.3 \%$ in the subtle condition, $1.1 \%$ in the blatant condition) explicitly placed blame on the Black child for the racism depicted in the vignette. Although this theme was rare, it represents a particularly concerning socialization message of victim-blaming. In response to the vignette about a White child telling her friends that they should not play with Black children (blatant racism), one parent suggested that perhaps the White child was telling another White child to avoid playing with the Black child because of the Black child's past behavior: "This one makes me think that maybe it has nothing to do with race. Maybe she wasn't nice to her at one point. But we don't know that. We don't know what's going on so let's just see." Another parent had a similar response to the vignette about a White child thinking all Black children are trouble makers (subtle racism):

Parent: Um... but the other boy, Jacob, a super friendly kid and never did anything wrong. Child: Yea but Jacob could've been a super duperParent: I mean there could've been a time Jacob did take something from somebody else, possibly. Child: Maybe cause he found it on the ground and he thought it was his.

Parent: That's true too...

\section{Combinations of Messages}

We also explored combinations of different types of messages about race voiced by parents during the discussion task. We examined how many parents expressed different combinations of color conscious, racial ignorance, and external attribution messages within or across their responses to the vignettes in the blatant and subtle conditions. Results for the blatant 
condition appear in Figure 2. The largest group - about a third of the sample - was parents who voiced only color conscious messages, followed by parents who voiced a mixture of color conscious ideology and racial ignorance (about a quarter of the sample).

\section{Figure 2}

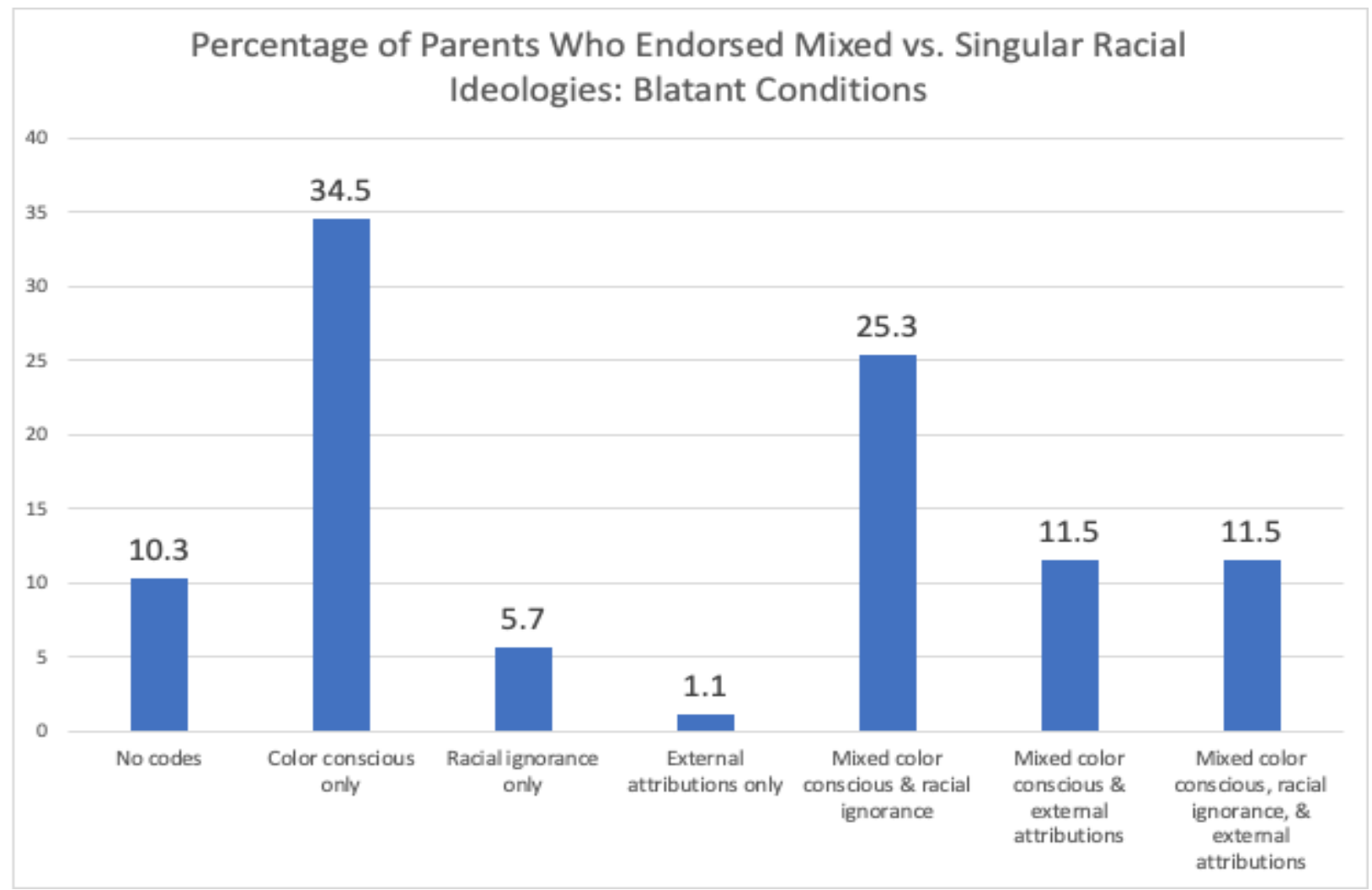

Results for the subtle condition appear in Figure 3. The largest group was parents who voiced a combination of color conscious ideology and racial ignorance $(28.7 \%)$, followed by parents who did not voice any codable racial ideologies (18.4\%), and parents who voiced only color conscious ideology (17.2\%). 


\section{Figure 3}

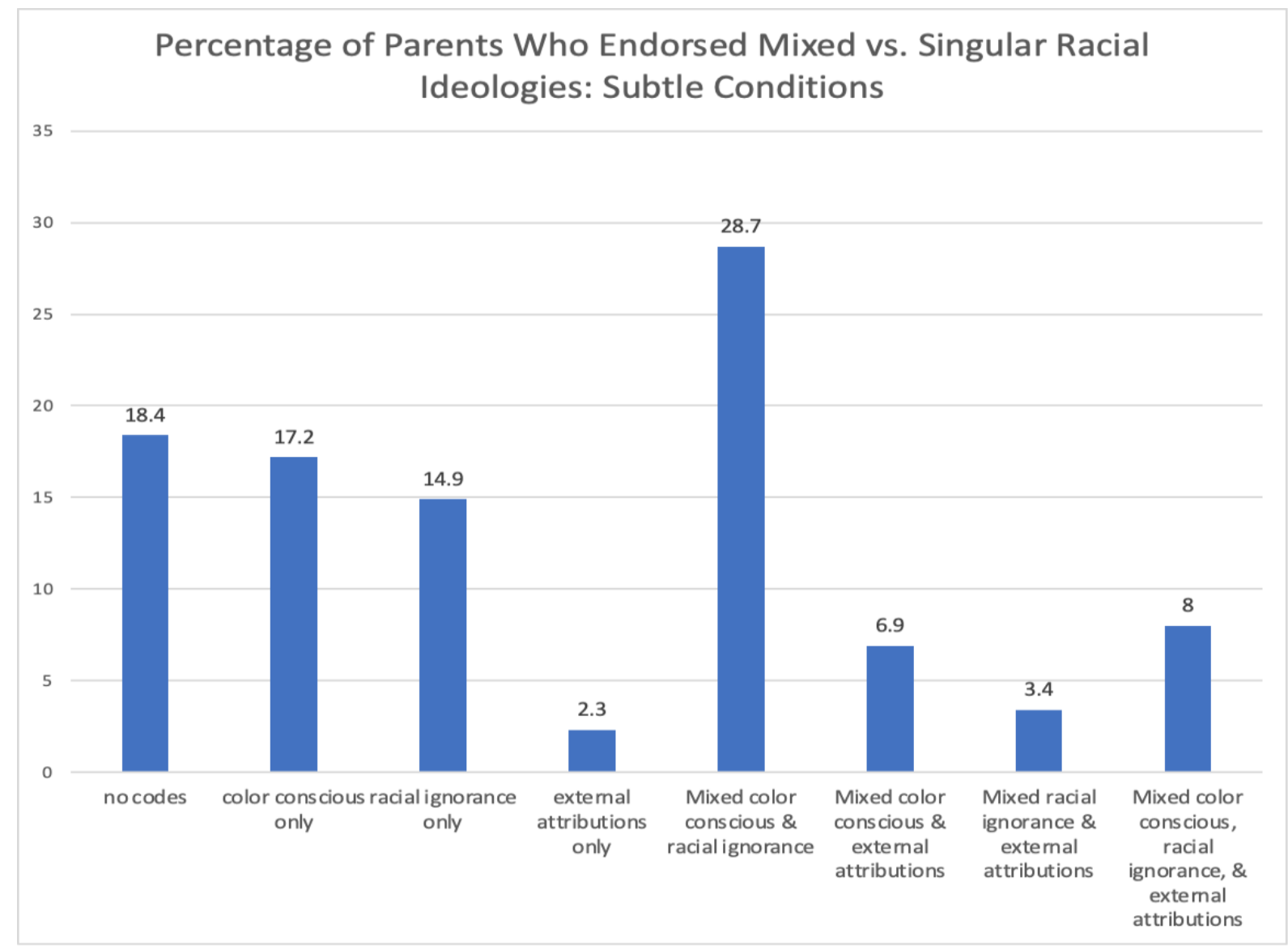

\section{Discussion}

The goal of this study was to evaluate the extent to which a new laboratory procedure, designed based on extant theory and research, elicited color conscious racial socialization among White U.S. parents. We conducted a qualitative analysis of the racial socialization messages communicated by White parents of children aged 8-12 during a guided racial discussion task. Our analysis revealed that, in stark contrast to prior research on White parents' racial socialization (e.g., Abaied \& Perry, 2021; Pahlke et al., 2012; Underhill, 2018; Vittrup, 2018; Zucker \& Patterson, 2018), the majority of parents used color conscious racial socialization methods and used racial labels during the discussion task. These results provide promising evidence that our procedure facilitated a greater willingness for White parents to point out racial 
prejudice to their children. However, our analysis also revealed that, even when provided with color conscious framing, a subset of parents endorsed messages that encouraged racial ignorance or external attributions for racist behaviors. Thus, this research also identifies ways that White parents push back against color conscious guidance, providing researchers with additional intervention targets in our ongoing efforts to foster anti-racist discussions in White families.

\section{Color Conscious Socialization Messages}

The extant literature on racial socialization among White parents and children has found that parents tend to avoid even mentioning race, let alone naming or unpacking racial prejudice. This well documented avoidance of racial discussions in White families was the impetus to develop a new approach to better facilitate these conversations. Consistent with our goal, the use of racial language and naming or pointing out prejudice was much more prevalent among White parents in our study than in past research. In the work of Vittrup and Holden (2011) as well as Pahlke and colleagues (2012), less than $10 \%$ of White parent-child conversations included references to race or topics consistent with color conscious socialization. In our study, over $75 \%$ of parents used racial labels and over $80 \%$ pointed out prejudice.

What might explain these dramatic differences? In both of these prior studies, the prompts used to elicit racial conversations (i.e., videos or storybooks) were selected for their depictions of racial diversity, positive interracial interactions, or representation of racial prejudice. However, one study primarily relied on existing children's television shows, and both studies included non-human characters or animals. In contrast, our video vignettes depicted novel, explicit instances (either subtle or blatant) of racial prejudice between Black and White children in familiar, everyday scenarios (e.g., classroom interactions, playing on the playground). These straightforward representations of racism may have helped White parents engage in color 
conscious socialization. In other words, relative to past work, the nature of our procedure left less room for White parents to avoid mentioning race (although some still did). It is also important to note that we targeted older children than some previous studies, such as Pahlke et al. (2012) and Vittrup and Holden (2011). White U.S. parents may be more willing to explicitly discuss race with 8-12-year-olds than they are with 4-7-year-olds. However, Abaied and Perry (2021) and Zucker and Patterson (2018) both found that approximately a third of White parents of children ages 8-12 self-reported ever having unprompted discussions of race with their children; thus, our task appears to have increased rates of discussion substantially compared to what White parents of children ages 8-12 have previously reporting doing on their own.

Although we observed high rates of racial labels and pointing out prejudice in response to our procedure, connections to racism in broader society were still quite rare. For most of the sample, prompting parents to consider whether prejudice had occurred and how it made the Black child feel did not lead them to make connections between the fictional examples they were discussing and interpersonal or structural racism as it occurs in our society. This suggests that, if meaningful engagement in anti-racism is our goal, White parents still have a long way to go. Perhaps White parents would be more likely to elaborate on how racism manifests in our society if they were provided with some education about systemic racism or prompts involving current events. Prior work that asked White parents how they discussed such events (e.g., the killings of Trayvon Martin and Michael Brown) with their children found little evidence of anti-racist messages (Abaied \& Perry, 2021), suggesting that White parents will need some scaffolding in this regard. A clear next step in this research is to explore how White parents respond if they are encouraged to help their child understand that fictional examples of racism are indicative of 
larger patterns of racism in society—something that a small number of parents in our sample were clearly capable of doing on their own.

\section{Racial Ignorance Socialization Messages}

The fact that approximately half of the sample expressed at least one form of racial ignorance, such as downplaying the role of race or casting doubt on the White child's racist intentions, is perhaps not surprising. We know from prior research that colorblind thinking tends to dominate White adults' perspectives on race, in general (e.g., Neville et al., 2013), as well as White parents' racial discussions with their children (e.g., Abaied \& Perry, 2021; Zucker \& Patterson, 2018). It would be overly optimistic to expect a set of structured prompts to completely override these trends. However, the forms of racial ignorance elicited by our guided discussion task differed somewhat from prior research that focused on White parents' reports of their prior racial discussions with children in early-to-middle childhood (Abaied \& Perry, 2021; Vittrup, 2018; Zucker \& Patterson, 2018), in which colorblindness was the most frequent socialization message. In our study, the prevalence of colorblindness was comparatively quite low; in addition, the rate of redirecting away from race, which is very similar to the denial of the reality of racism observed in Abaied and Perry's (2021) study, was also slightly lower in this sample. Instead, the most frequent form of racial ignorance was giving the White child the benefit of the doubt, particularly when discussing instances of subtle racism.

It is possible that the unique aspects of our study design may have led to parents' reduced tendencies to use colorblind language and more frequent use of giving the White child the benefit of the doubt. Specifically, the narratives within each video explicitly referenced the fact that the White child was treating the Black child differently because of their race. Although our method may have reduced the likelihood of parents' avoiding mentioning race, parents may have 
been more inclined to explain away what was described within the video narrative (e.g., stating that, although the video says that the White child's behavior was about racial discrimination, let's assume that it was not). Thus, relative to previous studies, this design perhaps set up a unique motivation for colorblind-oriented parents to counter the narrative that was provided to their child while they watched the video, which manifested in them giving the White child the benefit of the doubt, or making other attributions for their behavior.

One of our structured prompts asked parents and children to discuss why the White child did what they did (i.e., thinking or behaving in a racist way). The goal with this prompt was to encourage dyads to reflect upon the White child's racist thoughts or beliefs that may have spurred what was depicted in the vignette. However, we noted that, when parents made external attributions for the White child's behavior, many of them occurred in response to this prompt. Thus, it appears that asking parents to reflect on why the White child behaved in a racist way led them to speculate about the external source of the White child's bias (i.e., from whom or where they learned it) as opposed to the internal explanation (e.g., the child's racist attitudes or beliefs) for their racially prejudiced reaction or behavior. As such, perhaps a more pointed question about what the White child's behavior suggests about their attitudes or beliefs about Black people might better elicit the type of internal examination we were aiming for. Future work should examine this possibility.

\section{Implications for Future Intervention \& Prevention}

Our qualitative analysis provides valuable insight into the existing barriers to discussions of (anti-)racism between White parents and children and informs how researchers, educators, and activists may encourage White parents to more fully engage in anti-racist socialization. Since our procedure elicited more color conscious socialization messages than in previous work, future 
interventions might similarly utilize explicit examples of racism and requests for parents and children to reflect on the prejudice observed. Even among the parents in our sample who consistently pointed out prejudice, making connections to racism in broader society were still infrequent. This may be, in part, due to White parents' lack of engagement with examples of interpersonal or systemic racism. Interventions that aim to increase anti-racist socialization among White families may need to educate parents about systemic racism, and encourage them to recognize and sit with the many ways in which racism is embedded in our social relationships, systems, and structures in order to strengthen their ability to help their children understand these things.

We also found that our procedure seemed to elicit empathy for Black children who experience racism, from both parents and children. Our prompts were specifically designed to elicit perspective taking (what Batson \& Ahmad, 2009 refer to as Imagine-other perspective and Imagine-self perspective), by asking dyads to imagine how the Black child feels and how they would feel if they were that child. This type of perspective taking has been shown to reduce stereotyping and promote positive attitudes toward members of other groups (Batson \& Ahmad, 2009; Galinsky \& Moskowitz, 2000). We also found that in some cases parents spontaneously expressed empathic concern for the Black children who experienced racism (i.e., distress regarding the child's well-being). This form of empathy has been associated with improved attitudes toward outgroup members (Miklikowska, 2018), and increased negativity toward those doing them harm (Batson \& Ahmad, 2009). However, it is important to note that when negative attitudes are deeply entrenched, perspective taking can backfire (Batson \& Ahmad, 2009)_ which means that caution should be taken when using this kind of approach among White parents with strong racial biases. For example, evidence suggests that if one holds deep-seated 
negative attitudes toward outgroup members, imagine-other perspective taking (e.g., asking someone to imagine how an outgroup member feels when they experienced an adverse event) may lead them to engage in schadenfreude, taking pleasure in the outgroup member's suffering (Batson \& Ahmad, 2009). Empathy also has the potential to lead to paternalism, which may lead people to perceive outgroup members as dependent, and in need of their protection (Batson \& Ahmad, 2009). This is a disempowering perspective that likely feeds into societal narratives regarding White saviorism, and may ultimately serve to undermine the goals of anti-racism. Thus, even among well-meaning White parents who are supportive of equality, empathy at least has the potential to result in unintended consequences, such as seeing Black people as deficient and in need of White people to rescue them.

Clearly, there is a critical need for future anti-racism interventions specifically for White parents who socialize racial ignorance or make external attributions for racism in discussions about race with their children. Even though our procedure was largely effective in eliciting color conscious socialization, there were parents in our sample who still struggled to discuss race directly or accurately label the White child's behavior as racist. This suggests that some parents may not recognize how some of the interactions depicted in our videos reflect racism. Parental education and training programs that highlight historical and systemic connections to interpersonal instances of subtle racism (Bonam et al., 2019; Mukherjee et al., 2015; Salter \& Adams, 2016; Salter et al., 2018) may improve parents' ability to understand how racism operates and make these connections for their children. White parents might also need to become more comfortable with the topic of race, generally, in order to have effective, anti-racist conversations with their children. Interventions to support these White parents might begin by unpacking and reflecting upon their own discomfort regarding race conversations and reticence 
to identify racist behavior as such. Consistent with this idea, White parents who are higher in racial bias awareness (i.e., concerned about and aware of their racially biased tendencies) are more likely to acknowledge and less likely to deny the reality of racism (Perry et al., 2019). However, as previous evidence suggests, it is important to note that some White parents will be resistant to socializing their children in a color conscious way, such as those who choose to actively deny the reality of racism or think that discussing race is not relevant to their family (Abaied \& Perry, 2021; Abaied et al., 2021).

\section{Limitations and Future Directions}

This work needs to be considered in light of some limitations. Our procedure took place in a laboratory setting, which could have motivated parents to discuss the vignettes with their children in a more socially acceptable way (or a way that they hoped would make them appear unbiased) than they would have at home. We included multiple vignettes of both subtle and blatant racism, in part, because longer episodes of laboratory-based, parent-children interactions tend to facilitate more naturalistic behavior. Indeed, many parents endorsed socially undesirable messages (e.g., redirecting away race) in response to at least some of the vignettes and this suggests that, at least among those parents, social desirability was not so much of a concern. In addition, although the prompts were given as suggestions in order to facilitate color conscious conversations between dyads, many of the parents relied primarily on the prompts, discussing topics that fell within the scope of the prompts, but not going beyond that. Thus, it is possible that the prompts may have acted as a demand characteristic for parents, such that they felt the need to discuss the prompts that were provided in order to follow the instructions, which could have constrained the conversation in an artificial way. Moreover, as previously mentioned, although the majority of parents used some color conscious language when discussing the 
videos, some parents actively avoided discussing racism, and a few even blamed the Black child. These examples show that, although our method may increase color conscious language for some, it does not necessarily facilitate these kinds of conversations in all parents, nor are all parents motivated to encourage their children to be anti-racist.

Given our goal of introducing a novel procedure to support color conscious racial socialization among White parents, we focused on providing a detailed qualitative analysis of the content of parents' communication and determined that analyzing children's communication was beyond the scope of this report. Nonetheless, understanding children's responses to examples of racism and associations between White parents' racial socialization messages and their children's racial attitudes are important topics for future research. Finally, it is important to note that there are specific limitations with our sample. Our sample was primarily composed of mothers who were recruited from the greater Chicago area-which is a relatively liberal (our sample was $66 \%$ liberal-leaning) and racially and ethnically diverse city (approximately $30 \%$ non-Hispanic White, 30\% Black, 30\% Hispanic/Latinx, 7\% Asian, and 3\% multiracial; United States Census Bureau, 2019; albeit, consistent with much of the United States, highly racially segregated; Semuels, 2018). Moreover, on average, our sample was high in socioeconomic status (i.e., the majority had a family income of over $\$ 100,000$ and held undergraduate or graduate degrees). Thus, it is possible that, among different populations within different cultural contexts, our methods may have led to different kinds of conversations.

\section{Conclusion}

We believe that racial discussions in White families have an important role to play in the anti-racist movement. Our research provides promising, novel evidence that, by giving White parents support and guidance, we can start pushing the needle away from the colorblind status 
quo - highlighted in Kendi's 2019 book, How to be an Antiracist—and help White parents openly identify and condemn racism in discussions with their children. Although obstacles remain, we hope that parents, educators, scientists, and activists keep parent-child discussions in mind as one important piece of the puzzle in our ongoing efforts to create an anti-racist society. 


\section{References}

Abaied, J. L., Perry, S. P. (2021). Socialization of racial ideology by White parents. Cultural Diversity \& Ethnic Minority Psychology.

Abaied, J. L., Perry, S., Cheaito, A., \& Ramirez, V. (2021). Talking more and saying less: White parents' discussions of race-related current events before and after the 2020 Black Lives Matter protests. https://doi.org/10.31234/osf.io/w6qzn

Aboud, F. E. (2008). A social-cognitive developmental theory of prejudice. In S. M. Quintana \& C. McKown (Eds.), Handbook of Race, Racism, and The Developing Child (p. 55-71). John Wiley \& Sons, Inc.

Apfelbaum, E. P., Pauker, K., Sommers, S. R., \& Ambady, N. (2010). In blind pursuit of racial equality? Psychological Science, 21(11), 1587-1592. https://doi.org/10.1177/0956797610384741

Apfelbaum, E. P., Sommers, S. R., \& Norton, M. I. (2008). Seeing race and seeming racist? Evaluating strategic colorblindness in social interaction. Journal of Personality and Social Psychology, 95(4), 918-932

Araujo, L., \& Strasser, J. (2003). Confronting prejudice in the early childhood classroom. KappaDelta Pi Record, 39(4), 178-182.

Ashburn-Nardo, L., Morris, K. A., \& Goodwin, S. A. (2008). The confronting prejudiced responses (CPR) model: Applying CPR in organizations. Academy of Management Learning \& Education, 7(3), 332-342

Batson, C.D., \& Ahmad, N. Y. (2009). Using empathy to improve intergroup attitudes and relations. Social Issues and Policy Review, 3(1), 141-177. 
Boisjoly, J., Duncan, G. J., Kremer, M., Levy, D. M., \& Eccles, J. (2006). Empathy or antipathy? The impact of diversity. American Economic Review, 96(5), 1890-1905.

Bonam, C. M., Nair Das, V., Coleman, B. R., \& Salter, P. (2019). Ignoring History, Denying Racism: Mounting Evidence for the Marley Hypothesis and Epistemologies of Ignorance. Social Psychological and Personality Science, 10(2), 257-265. https://doi.org/10.1177/1948550617751583

Brey, E., \& Pauker, K. (2019) Teachers' nonverbal behaviors influence children's stereotypic beliefs, Journal of Experimental Child Psychology, 188, 104671. https://doi.org/10.1016/j.jecp.2019.104671.

Cox, D., Navarro-Rivera, J., Jones, R.P. (2016) Race, Religion, and Political Affiliation of Americans' Core Social Networks. PRRI. https://www.prri.org/research/poll-racereligion-politics-americans-social-networks/.

Cox, W. T., \& Devine, P. G. (2019). The prejudice habit-breaking intervention: An empowerment-based confrontation approach. In Confronting Prejudice and Discrimination (pp. 249-274). Academic Press

Dovidio, J. F., Ten Vergert, M., Stewart, T. L., Gaertner, S. L., Johnson, J. D., Esses, V. M., ... \& Pearson, A. R. (2004). Perspective and prejudice: Antecedents and mediating mechanisms. Personality and Social Psychology Bulletin, 30(12), 1537-1549.

Galinsky, A. D., \& Moskowitz, G. B. (2000). Perspective-taking: Decreasing stereotype expression, stereotype accessibility, and in-group favoritism. Journal of Personality and Social Psychology, 78, 708-724.

Hagerman, M. A. (2017). White racial socialization: Progressive fathers on raising "antiracist" children. Journal of Marriage and Family, 79(1), 60-74. 
Hagerman, M.A. (2018). White Kids: Growing Up with Privilege in a Racially Divided America. New York: New York University Press.

Hetey, R. C., \& Eberhardt, J. L. (2018). The numbers don’t speak for themselves: Racial disparities and the persistence of inequality in the criminal justice system. Current Directions in Psychological Science, 27(3), 183-187

Hughes, J., Bigler, R., \& Levy, S. (2007). Consequences of learning about historical racism among European American and African American children. Child Development, 78, 1689-1705. doi:10.1111/j.1467-8624.2007.01096.x

Jefferson, H., Neuner, F. G., \& Pasek, J. (2017). Seeing blue in Black and White: Race and perceptions of officer-involved shootings. Perspectives on Politics, 1-19

Jones, R. P. (2014). Self-Segregation: Why It's So Hard for Whites to Understand Ferguson. The Atlantic. https://www.theatlantic.com/national/archive/2014/08/self-segregation-why-itshard-for-whites-to-understand-ferguson/378928/.

Kendi, I. X. (2019). How to be an antiracist. One World: New York, NY.

Killen, M., Rutland, A., \& Ruck, M. D. (2011). Promoting Equity, Tolerance, and Justice in Childhood. Social Policy Report. 25(4). Society for Research in Child Development.

Loyd, A. B., \& Gaither, S. E. (2018). Racial/ethnic socialization for White youth: What we know and future directions. Journal of Applied Developmental Psychology. Advance online publication. doi:10.1016/j.appdev.2018.05.004

Mallett, R. K., Huntsinger, J. R., Sinclair, S., \& Swim, J. K. (2008). Seeing through their eyes: When majority group members take collective action on behalf of an outgroup. Group Processes \& Intergroup Relations, 11(4), 451-470. 
Masten, Carrie \& Gillen-O'Neel, Cari \& Brown, Christia. (2010). Children's intergroup empathic processing: The roles of novel ingroup identification, situational distress, and social anxiety. Journal of Experimental Child Psychology. 106. 115-28. https://doi.org/10.1016/j.jecp.2010.01.002.

Miklikowska, M. (2018). Empathy trumps prejudice: The longitudinal relation between empathy and anti-immigrant attitudes in adolescence. Developmental Psychology, 54(4), 703-717. http://dx.doi.org/10.1037/dev0000474

Mukherjee, S., Salter, P. S., \& Molina, L. E. (2015). Museum spaces as psychological affordances: Representations of immigration history and national identity. Frontiers in Psychology, 6(May), 1-16. https://doi.org/10.3389/fpsyg.2015.00692

Nelson, J. K., Dunn, K. M., \& Paradies, Y. (2011). Bystander Anti-Racism: A Review of the literature. Analyses of Social Issues and Public Policy, 11(1), 263-284. https://doi.org/10.1111/j.1530-2415.2011.01274.x

Neville, H. A., Awad, G. H., Brooks, J. E., Flores, M. P., \& Bluemel, J. (2013). Color-blind racial ideology: Theory, training, and measurement implications in psychology. American Psychologist, 68(6), 455-466. https://doi.org/10.1037/a0033282

Neville, H. A., Lilly, R. L., Duran, G., Lee, R. M., \& Browne, L. (2000). Construction and initial validation of the color-blind racial attitudes scale (CoBRAS). Journal of Counseling Psychology, 47(1), 59.

Olson, K. R., Dweck, C. S., Spelke, E. S., \& Banaji, M. R. (2011). Children's responses to group-based inequalities: Perpetuation and rectification. Social Cognition, 29, 271-288. 
Pachter, L. M., Bernstein, B. A., Szalacha, L. A., \& Coll, C. G. (2010). Perceived racism and discrimination in children and youths: An exploratory study. Health \& Social Work, 35(1), 61-69.

Pahlke, E., Bigler, R. S., \& Suizzo, M.-A. (2012). Relations between colorblind socialization and children's racial bias: Evidence from European American mothers and their preschool children. Child Development, 83, 1164-1179. doi:10.1111/j.1467-8624.2012.01770.x

Perry, S. P., Skinner, A. L., \& Abaied, J. L. (2019). Bias awareness predicts color conscious racial socialization methods among White parents. Journal of Social Issues, 1075, 10351056.

Pettigrew, Thomas F., and Linda R. Tropp. (2000) "Does Intergroup Contact Reduce Prejudice: Recent Meta-Analytic Findings." In Reducing Prejudice and Discrimination, ed. Stuart Oskamp, 93-114.

Pew Research Center. (2014, December 8). Sharp racial divisions in reactions to Brown, Garner decisions. https://www.pewresearch.org/politics/2014/12/08/sharp-racialdivisions-in-reactions-to-brown-garner-decisions/

Roberts, S. O., \& Rizzo, M. T. (2020). The psychology of American racism. American Psychologist. Advance online publication. https://doi.org/10.1037/amp0000642

Rutland, A., \& Killen, M. (2015). A developmental science approach to reducing prejudice and social exclusion: Intergroup processes, social-cognitive development, and moral reasoning. Social Issues and Policy Review, 9(1), 121-154.

Salter, P. S., \& Adams, G. (2016). On the intentionality of cultural products: Representations of Black history as psychological affordances. Frontiers in Psychology, 7(August), 1-21. https://doi.org/10.3389/fpsyg.2016.01166 
Salter, P. S., Adams, G., \& Perez, M. J. (2018). Racism in the Structure of Everyday Worlds: A Cultural-Psychological Perspective. Current Directions in Psychological Science, 27(3), 150-155. https://doi.org/10.1177/0963721417724239

Scott, K. E., Shutts, K., \& Devine, P. G. (2020). Parents' role in addressing children's racial bias: The case of speculation without evidence. Perspectives on Psychological Science, 15 (5), 1178-1186. https://doi.org/10.1177/1745691620927702.

Seaton, E. K., \& Douglass, S. (2014). School diversity and racial discrimination among AfricanAmerican adolescents. Cultural Diversity and Ethnic Minority Psychology, 20(2), 156165. https://doi.org/10.1037/a0035322

Semuels, A. (2018). Chicago's awful divide. The Atlantic. https://www.theatlantic.com/business/archive/2018/03/chicago-segregationpoverty/556649/.

Sigelman, L., Bledsoe, T., Welch, S., \& Combs, M. W. (1996). Making contact? Black-white social interaction in an urban setting. American Journal of Sociology, 101(5), 1306-1332.

Sommers, S. R., \& Norton, M. I. (2006). Lay theories about White racists: What constitutes racism (and what doesn't). Group Processes \& Intergroup Relations, 9, 117-138. https://doi.org/10.1177/1368430206059881

Sue, D. W., Capodilupo, C. M., Torino, G. C., Bucceri, J. M., Holder, A., Nadal, K. L., \& Esquilin, M. (2007). Racial microaggressions in everyday life: implications for clinical practice. American Psychologist, 62(4), 271.

Underhill, M. R. (2018). Parenting during Ferguson: making sense of White parents' silence. Ethnic and Racial Studies, 41 (11), 1934-1951. doi:10.1080/01419870.2017.1375132 
United States Census Bureau. (2019). QuickFacts: Chicago city, Illinois [Data file]. Retrieved from https://www.census.gov/quickfacts/chicagocityillinois

Vescio, T. K., Sechrist, G. B., \& Paolucci, M. P. (2003). Perspective taking and prejudice reduction: The mediational role of empathy arousal and situational attributions. European Journal of Social Psychology, 33(4), 455-472

Vittrup, B. (2018). Color blind or color conscious? White American mothers' approaches to racial socialization. Journal of Family Issues, 39, 668-692.

doi:10.1177/0192513X16676858

Vittrup, B., \& Holden, G. W. (2011). Exploring the impact of educational television and parentchild discussions on children's racial attitudes. Analyses of Social Issues and Public Policy, 11, 82-104. doi:10.1111/j.1530-2415.2010.01223.x

Zucker, J. K., \& Patterson, M. M. (2018). Racial socialization practices among White American parents: Relations to racial attitudes, racial identity, and school diversity. Journal of Family Issues, 39, 3903-3930. https://doi.org/10.1177/0192513X18800766 